\title{
Social Media Responses and Brand Personality in Product and Moral Harm Crises: Why Waste a Good Crisis?
}

\begin{abstract}
When a brand crisis happens, a manager needs to be ready to mitigate its potentially damaging effects. The purpose of this research is to understand the process of attitudinal changes towards a brand in a crisis and the brand's communication around the crisis by utilising balance theory and brand personality. Four crisis case studies were selected based on type of crisis, scale of crisis (national/international), organisation business model (franchise or nonfranchise) and recency of the crisis. We collected data from brands' Twitter platforms three months on either side of the crisis event horizon. Results demonstrate an opportunity to update the balance theory approach in a crisis by considering the type of crisis (product harm vs. moral harm) relative to brand personality (brand competence vs. brand character). Balance theory helps explain how consumer attitude changes occur through a crisis. Further, the mapping of brand communications in social media over four selected case studies show that brand personality identity can change as a result of a crisis and demonstrate how brand managers can actively frame their online communication to help the brand to recover more effectively from a crisis.
\end{abstract}

\section{Statement of Contribution}

This research makes a theoretical and empirical contribution to brand management in a crisis by extending balance theory into the understudied intersection of brand personality and crisis type. It does this by examining both the consumer attitudinal changes expressed in social media during a crisis and the subsequent brand management response. A methodological contribution is made by accounting for both perspectives in one paper.

Keywords: Brand Crisis; Brand Management; Consumer Sentiment, Social Media, Balance Theory, Brand Personality 


\section{Introduction}

Establishing a solid reputation, developing a distinct identity and forging key messages to communicate to consumers are tried-and-tested building blocks to branding (D. Aaker, 1996). Whilst practitioners and academics understand these approaches, this does not prevent even the most experienced and well-established brands from experiencing crises. A crisis situation extends beyond the regular negative word of mouth that circulates about a brand, and is defined as an intense and broadly communicated negative storyline about the brand (Dawar and Lei, 2009; Scholz and Smith, 2019). Events that precipitate a brand crisis are varied and may involve unsafe components being found in products (e.g. Samsung's Galaxy Note 7 combustible batteries) or poor treatment of consumers (e.g. British Airways poor security and privacy breach of data). Crucially, brand crises often impact negatively on consumers as well as other stakeholders, such as shareholders, government regulators and - in some cases - employees.

As for many reputational issues, a brand is only as resilient as its ability to withstand unfavourable information about it (Copulsky, 2011). Social media has enabled consumers to discuss brands in a more open manner which tends to accelerate communication (Rauschnabel, Kammerlander, \& Ivens, 2016). In the past, dissatisfied customers might have written a letter of complaint to a brand's head office. Today, however, consumers can easily express a complaint through social media for all to see instantly (Veil, Buehner, \& Palenchar, 2011). This ease of communication represents a shift in power for consumers (Rauschnabel, et al., 2016), so brands now actively monitor the conversations about them in public fora. Assessing conversations and attitude changes in social media enables brand managers to identify the patterns and trends surrounding a crisis and helps them to navigate a way forward.

A crisis forces the consumer to reassess their thoughts about a brand through the pressure of cognitive dissonance. Cognitive dissonance is discomfort caused by simultaneously developing or holding contradictory beliefs (Brehm and Cohen, 1962). When a brand crisis happens, loyal customers might be unable to maintain cognitive consistency (Cartwright and Harary, 1956). Consumer information processes following a crisis are therefore crucial to how a brand might recover. While cognitive dissonance explains the effort consumers experience to reconcile their beliefs about a brand in crisis, Heider's (1958) balance theory provides a more nuanced perspective about the processing of brand information which could be contradicting beliefs about the brand. How the brand reacts, as well as the social media "buzz", could influence perception leading to three key consumer outcomes: (1) reconfirm previous beliefs about the brand (2) adopt a new and less favourable view of the brand, or (3) conclude that the alleged negative information is inconsistent with the brand and therefore untrue. Given the ease with which consumers can join in the conversation on social media, balance theory could 
provide a unique insight into how brands and consumers interact and react before, during and after a crisis.

Whilst negativity in conversations about a brand can lead to or intensify a crisis, brands which encourage and develop conversations reflecting their values amid a crisis can find an easier way to get back to where they once were in terms of stakeholder perception (V. Roy, Tata, \& Parsad, 2018). When something goes wrong and a crisis develops, consumers will give credit for brands that offer appropriate explanations along with an apology (L. Wang, Wang, Keller, \& Li, 2016). However, consumer reaction is also influenced by the type of crisis that can be based on a performance issue (product harm) or a fault in character (moral harm) (Baghi and Gabrielli, 2019). This categorisation of crises reflects a similar distinction in the dimensions of brand personality along the lines of competence and warmth (Fiske, Cuddy, \& Glick, 2007). Humans tend to anthropomorphise brands with human characteristics to facilitate the formation of a relationship (J. Aaker, 1997). While this is an important stream of brand research, there has been little brand personality research on brand crises, particularly at the intersection with social media.

The purpose of this research is to understand the process of brand crisis management through consumer attitude (sentiment change) and brand communication (personality change) in a crisis by utilising balance theory as the theoretical lens. The underlying research question is: how are changes in consumer attitude toward a brand and its communicated personality affected by different crisis types? This paper reviews research in salient areas to illustrate key research gaps and to highlight where this study contributes. This is followed by a discussion of the theoretical framework and case study approach to investigate brand crises through a balance theory lens. The case analysis discussion presents key findings and the final discussion focuses on the main implications of the research.

\section{Literature Review}

Brand crises can result from true negative stories surfacing in the public sphere (Liu, Shankar, \& Yun, 2017; Souiden and Pons, 2009) or can result from false rumours about the brand (Dawar and Lei, 2009; Vafeiadis, Bortree, Buckley, Diddi, \& Xiao, 2019). Sometimes, brands can control the crisis discourse by voluntarily disclosing an issue but, at other times, a third party may release information which instigates a crisis for the brand (Souiden and Pons, 2009; Yannopoulou, Koronis, \& Elliott, 2011). An examination of brands in crises necessitates a clear definition. A seminal paper on the subject describes brand crises in the rumour context as situations which are characterised by highly publicised and false negative ideas that impact the 
brand image (Dawar and Lei, 2009). Yet, this definition ignores the type of brand crises that result from true issues that become highly publicised and can negatively affect the brand image. Therefore, a more inclusive definition of brand crisis would more broadly relate to all highly publicised and negative ideas about the brand that have the potential to affect the image of the brand. $\mathrm{K}$. Xu and $\mathrm{Li}$ (2013) describe the characteristics of crisis events as unexpected, provide for limited response time, are associated with severe consequences and threaten the underlying brand value. A brand crisis is associated with significant consequences and is distinct from social media "firestorms" which are characterised by short and intense negative electronic word-of-mouth communications (Herhausen, Ludwig, Grewal, Wulf, \& Schoegel, 2019; Scholz and Smith, 2019). Therefore, brand crises are significant events exceeding in exposure and impact of typical negative word of mouth communications among consumers.

While a brand crisis is defined as having a significant negative impact on the brand image, the type of crisis can impact the effects on the brand and research has approached this in different ways. For instance, Dawar and Lei (2009) investigate factors that can influence the effects of the crisis on the brand and find that crisis relevance and familiarity with the brand had a significant interaction with evaluations of the brand. Further, this relationship is influenced by the crisis severity facing the brand. Other research finds that differences in the level of consumer involvement is a means to explain differential impacts of a brand crisis, where the brand management response may be viewed as more credible among highly involved consumers, whereas a rumour source may be viewed as more credible among low involvement consumers (Vafeiadis, et al., 2019).

Research on brand crises has developed around two main categories of crisis type: product harm and moral harm crises. Product harm crises have been more dominant in research to understand the effects on the brand and are those situations occurring with defective product issues or when the products themselves are dangerous with the potential to cause injury to consumers (S. Lee and Atkinson, 2019; Liu, et al., 2017; Rea, J. Wang, \& Stoner, 2014; V. Roy, et al., 2018; Souiden and Pons, 2009). In other words, this type of crisis places the competence aspects of the brand image at risk because it is about the brand's performance. For example, Souiden and Pons (2009) investigate product recalls in the automotive industry and find that recalls had a significant and negative effect on the brand image, loyalty to the brand and brand purchase intentions. Further, Liu, et al. (2017) examine the effects of an automotive recall over time and find that the effects can extend through a full year. While the negative effects of a product harm crisis can have a long term effect, these effects can be mitigated through voluntary recall (Souiden and Pons, 2009) and subsequent efforts to remediate the situation for consumers (Liu, et al., 2017). V. Roy, et al. (2018) suggest that the restoration of the brand from a product 
harm crisis results from a strong emotional connection between the consumer and the brand along with the ability to trust and see the brand as authentic. Brands with a strong and established equity base can also expect to experience some protection from the negative effects of a product harm crisis (Rea, et al., 2014).

Although product harm crises have historically drawn much attention in the literature, research has more recently explored the moral harm type of crisis (Baghi and Gabrielli, 2019; Hegner, Beldad, \& Hulzink, 2018; Thaler, Herbst, \& Merz, 2018). These crises represent significant rumours or lapses in the character or values of the brand as opposed to the performance related issues of a product harm crisis. Certainly, moral harm crises can have a negative effect on the brand (Baghi and Gabrielli, 2019; Hegner, et al., 2018; Thaler, et al., 2018). However, research does provide some insight as to how brand managers can mitigate these negative effects. For instance, Thaler, et al. (2018) examine Volkswagen's recent emission scandal and provided support for the assertion that brand equity can help protect a brand from moral harm risks. The communication strategy employed by the brand management can also impact the moral harm crisis effects. Hegner, et al. (2018) find that proactive disclosure by the brand of a lapse in values can mitigate the risks to the brand image as opposed to when consumers learn about the moral harm crisis through a third party. In addition, Baghi and Gabrielli (2019) compare product harm versus moral harm crises across two different cultures and find that those from a more collectivist culture have a harsher reaction to a moral harm crisis than to a product harm crisis. While this research highlights aspects for brand managers to consider in a brand crisis, there has been little research examining the sensemaking process of consumers over time for a crisis.

Brand research on moral crises has also examined the impact of moral transgressions by associated actors (e.g. athletes) on sponsoring or endorsed brands (Hur, Lim, Won, \& Kwon, 2018; J. Lee and Kwak, 2016). In this research, moral coupling is provided as rationale for consumer processing of the individual's transgression when a linkage is drawn between morality and performance leading to negative evaluations of the endorsed brand (J. Lee and Kwak, 2016). This explanation is most relevant when the moral transgression is already associated with performance, but can depend on the moral reasoning approach utilised by the consumer (J. Lee and Kwak, 2016). If consumers are able to de-couple the moral transgression from performance, more favourable attitudes toward the endorsed brand are likely (Hur, et al., 2018). Similarly, research regarding the purchase of counterfeit goods shows that moral decoupling provides a good explanation of consumer intentions (Orth, Hoffmann, \& Nickel, 2019). Orth, et al. (2019) show that these effects result from positive emotions associated with the purchasing process (e.g. ease and pleasantness). This is important to note because both 
positive and negative emotions are evoked in moral brand crises. However, moral reasoning may not apply to all crises and an alternative explanation to the sense-making process is needed.

The intersection of research on branding, crises and social media is also drawing some recent attention. Research explores general social platforms (Pace, Balboni, \& Gistri, 2017) and the specific Facebook platform (Han, Sung, \& Kim, 2018; S. Lee and Atkinson, 2019; Mishra and Sharma, 2019). Social media and brand crisis research has investigated both true crisis situations (Pace, et al., 2017) as well as those that are false (Vafeiadis, et al., 2019). This research has at times extended to understand impact and reactions. Research into the effects of a brand crisis in social media demonstrate that social media has the power to help to spread and intensify reactions to a crisis (Pace, et al., 2017). Pace, et al. (2017) investigate the effects of a Barilla family business spokesperson making homophobic comments in social media and find that social media can multiply the crisis effects. However, other research shows that social media can also function to mediate the effects of a crisis when counter-critical comments are made by committed consumers (Mishra and Sharma, 2019). Mishra and Sharma (2019) conduct a sentiment analysis on comments made by people using Facebook following news that the Maggi brand of noodles were contaminated. Vafeiadis, et al. (2019) suggests that, in the case of a false negative crisis, that attacking the credibility of the source in social media is a better option than a direct rebuttal to the rumour's substance. Therefore, the social networks activated through various platforms can influence crisis effects while the direction depends on the actors expressing their voice. While research has explored different crisis types based on competence (Mishra and Sharma, 2019) and those based on character (Pace, et al., 2017), no direct comparison seems to have been made in crisis effects through social media. This represents an important gap in the literature. In addition, few studies seem to have focused specifically on the Twitter platform which may provide some different insight due to the quicker and shorter nature of exchanges between people in a social network.

\section{Brand Personality}

While brand crises create a large risk for the image of the brand, the personification of brands can provide an important way to look at brand image in times of peril. The anthropomorphising of brands means that consumers are attaching human attributes to brands (J. Aaker, 1997) to enable the formation of relationships (Bennett and Hill, 2012). Brand personality has also been described as being about the character of the brand (Plummer, 2000). Therefore, the idea of character is particularly pertinent when considering situations where a brand crisis occurs out of a perceived failure in performance or values. 
Brand personality developed into a trait-based approach with the seminal J. Aaker (1997) paper delineating five dimensions of brand personality - Competence, Excitement, Ruggedness, Sincerity and Sophistication - reflecting the work by psychologists to understand human personalities. Recent research on brand personality has winnowed the dimensionality down to focus on critical aspects. For instance, both Bosnjak, Bochmann, \& Hufschmidt (2007) and Okazaki (2006) identify fewer brand personality dimensions. In particular, Okazaki (2006) describes a dual dimension structure of brand personality consisting of exciting and sophisticated dimensions. This reinforces two of J. Aaker (1997) dimensions, but the more recent work emphasises brand personality on dimensions of warmth and competence (Jennifer Aaker, Vohs, \& Mogilner, 2010; S. Fiske, C. Malone, \& N. Kervyn, 2012; MacInnis, 2012). This is consistent with the development of personality research that describes people based on warmth/character and competence/performance (Fiske, et al., 2007). While the performance aspect is clear, the warmth dimension has been described as the intentions towards or treatment of the consumer by the brand (Jennifer Aaker, et al., 2010; S. T. Fiske, C. Malone, \& N. Kervyn, 2012; MacInnis, 2012), reflecting underlying values. While all five dimensions may be important, the competence and warmth aspects are likely to be key for product and moral harm crises.

Given that brand personality is the character of the brand (Plummer, 2000), a crisis related to character can present an opportunity for changes in brand personality. Brand personality has been shown to be flexible in the context of changes, such as, brand extensions when consumers view the traits themselves as being malleable (Yorkston, Nunes, \& Matta, 2010). Other scholars have argued that incongruency can occur when the consumer no longer views the brand as consistent with their own sense of self (Klipfel, Barclay, \& Bockorny, 2014). In other words, a moral- or performance-based crisis may impact assessments of relevant dimensions of brand personality (e.g. sincerity, competence) if there is an inconsistency with the consumer's beliefs about themselves. Certainly, changes in brand personality do occur (Bergkvist, 2017). For instance, Bergkvist (2017) shows that personality traits of a celebrity endorser can influence the brand personality of an unfamiliar brand. So, despite the stability of brand images, brand personality is a brand image lens that is subject to changes by consumers under certain conditions.

Research at the intersection of brand personality and brand crises has been limited but explores aspects of brand personality that might be more sensitive to crisis situations. Han, et al. (2018) compare two brands based on the emphasis of their brand personalities (i.e. sincere versus exciting). The categorisation is related to the current research because the two dimensions are similar to the distinction between performance and character. Han, et al. (2018) 
find that sincere-oriented brands tend to be more active in their management strategies of communications in social media compared to the more excited-oriented brands which are more passive. Another study shows that open communications are more positive than a defensive response particularly with sincerity perceptions for sophisticated brands (Xia, 2013). This suggests that messaging consistent with the brand personality will be beneficial for the brand recovery. However, there has been little research exploring changes of brand personality identity communicated throughout a brand crisis, particularly accounting for differences in crisis type.

While research into brand crises are growing, the current study addresses an important intersection of research gaps. First, there has been little research directly comparing product harm versus moral harm crises. Second, little attention has been paid to exploring the sensemaking process of consumers over time for a crisis. Third, a stream of research has applied moral reasoning to understand consumer reaction in a crisis, however, this does not apply for all crises and other explanations about the sense-making process are needed. Fourth, crisis studies have not focused specifically on the Twitter platform and a deeper understanding may be found given the nature of the social networking platform. Fifth, brand personality is a critical lens for a brand, yet the management response to a crisis in this perspective has not been examined.

\section{Theory Framework}

The research gaps can be addressed within a framework of balance theory to better understand how consumer attitude is reconciled towards a brand crisis over time. Balance theory provides an excellent basis for this because it is largely about consumers' desire to maintain harmony among a set of related attitudinal objects. Heider's (1958) model describes a relationship triad among a person, another person and an object. The relationship triad is balanced when there are positive sentiments held towards each attitudinal object. However, if there is a sentiment change for one relationship, the entire relationship triad can be compromised and the consumer experiences cognitive distress. The consumer is then motivated to relieve this situation by rebalancing the relationship triad.

Balance theory requires the identification of relevant brand objects in the consumerbrand relationship and Figure 1 below highlights the three central attitudinal objects: customer, brand, and action toward the brand. The relationships between the key attitudinal objects described by Heider (1958) can be measured as sentiment and characterised as positive (e.g. liking) or negative (e.g. disliking). This relational triad forms the basis of the current study to explore possible changes with a brand crisis. According to Heider's (1958) balance theory and 
research previously cited, a brand crisis situation can put the consumer into cognitive distress with changes in triad-based attitudes. Indeed, the changes may result in unbalancing the triad, motivating the consumer to reassess the entire triad or parts of it to re-stabilise the relationship triangle.

Figure 1: Heider's (1958) balance theory in relation to brand crisis

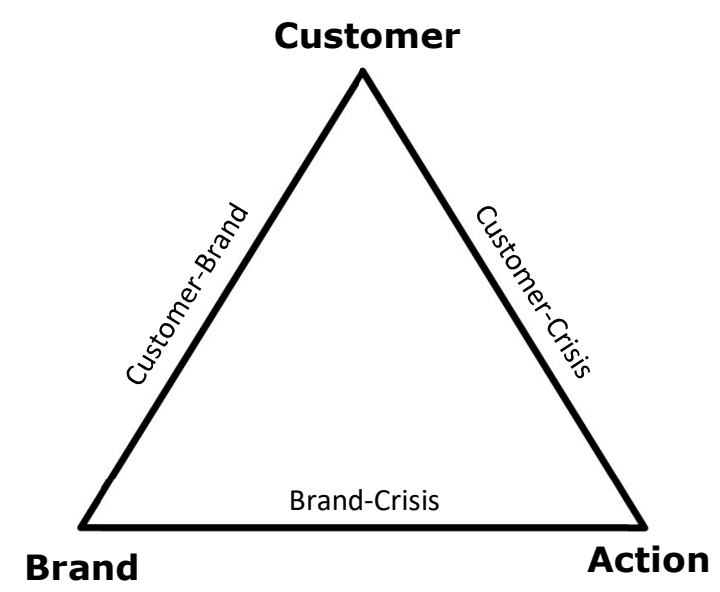

Balance theory has been applied and extended in consumer behaviour research. Importantly, balance theory has been linked to attitudes and attitude changes (Woodside and Chebat, 2001). Balance theory has also been shown to explain relationships among consumers and their brands (Hammerl, Dorner, Foscht, \& Brandstätter, 2016). While balance theory is criticised for its simplicity, the parsimony of focusing on key attitudinal relationships through a triad represents a powerful way to integrate concepts (S. Roy, Gammoh, \& Koh, 2012) especially in the context of complex social networks (Yang and Bentley, 2017). However, there has been very little work using balance theory to explain altitudinal triad changes over time (Rawlings and Friedkin, 2017).

From a branding perspective, Baxter and Ilicic (2015) investigate a triangle of brand relationships between a brand, a charity and a celebrity to specifically examine when an imbalance occurs as either a positive (i.e. two positive and one negative attitude) or negative (i.e. two negative and one positive) dominant imbalance. Their study shows that brand purchases are more likely in a balanced triad scenario, but that purchases are also possible in the positive imbalance situation. Hammerl, et al. (2016) examine symbolic brand meaning in the relationships of brands, consumers and reference groups using balance theory to show that high symbolic meaning does not occur when there is a strong connection to a brand used by an outgroup or when there is a weak connection to a brand used by an in-group. In another study, Yun, Duff, Vargas, Himelboim, \& Sundaram (2019) use balance theory to better understand 
brand fit with a cause marketing initiative. They found that consumers' views of cause marketing fit are based on its triangle relationship with brand and cause attitudes. Zhang and Borden (2017) use balance theory to explain changes in stakeholder scepticism during crisis situations. They focus on corporate social responsibility initiative fit with the issue and do not examine the nature of the crisis itself. In their study, initiative fit with the crisis leads to reduced stakeholder scepticism. Although the current research has a different aim, balance theory provides a valuable theoretical frame offering insight into how potential attitude and brand personality changes can occur temporally around a crisis.

\section{Crisis Context and Brand Management}

As described in the literature review, previous research has identified two dominant crisis types: product harm (S. Lee and Atkinson, 2019; Liu, et al., 2017; Rea, et al., 2014; V. Roy, et al., 2018; Souiden and Pons, 2009) and moral harm (Baghi and Gabrielli, 2019; Hegner, et al., 2018; Thaler, et al., 2018). Product harm occurs when a systemic performance issue causes physical harm or presents a significant failure to perform. Although these issues have drawn much attention in the literature, research is now focusing on moral harm crises pertaining to lapses in judgment or values associated with the brand. We can expect changes in consumer attitude toward the brand in a crisis situation (Dawar and Lei, 2009) and know that the response from brand managers can influence consumer attitudes (Vafeiadis, et al., 2019). In addition, research on moral de-coupling suggests that attitudes toward the crisis can also matter (Hur, et al., 2018; J. Lee and Kwak, 2016). However, there is little temporally based research to examine consumer reactions before, through and after a crisis situation - particularly research that examines both crisis types and in the context of attitudes toward the crisis and brand response. Therefore, Hypothesis 1 is generally stated.

Hypothesis 1: Attitude toward the brand, crisis and response that become unbalanced during a crisis will rebalance again after the crisis.

Brand personality research is a popular area of study but there are few intersections with crises examining effects throughout the crisis and with both crisis types. Although brand personality provides an important lens on brand image based on character (Plummer, 2000) and brand personality can be malleable (Bergkvist, 2017; Klipfel, et al., 2014; Yorkston, et al., 2010), there is insufficient research to suggest directional differences for crisis types or potential brand personality changes in a crisis. In addition, the reaction of management is likely to play a role (Han, et al., 2018; Xia, 2013). While research on brand crises in social media has increased, the Twitter platform is not often examined, nor is the brand personality perspective often examined in social media. Therefore, the current research seeks to close these gaps in the 
literature and examine the following generally stated hypothesis to reflect the nature of case study research focused on deepening our understanding about how brand personality changes throughout a crisis.

Hypothesis 2: There will be changes in brand personality dimensions when comparing pre-, during and post-crisis timeframes of two crisis types (product and moral harm).

\section{Methodology}

To understand the nature of consumer conversation surrounding a crisis, an exploratory methodology was selected involving multiple cases of crises. Case studies are most appropriate for research like this, where the emphasis is on understanding the how and why of a phenomenon (Yin, 2017). In general, we are seeking to deepen understanding of consumer reactions to brand crisis situations. There is no typical case study design in marketing research (Beverland and Lindgreen, 2010) and this research uses a multiple case study design to enable the comparison of key differences as well as broaden the impact of findings. For multiple case study approaches, each entity needs to be similar in some fashion (Stake, 2006).

\section{Sample Selection}

In this research, the selected brand cases all faced a significant image crisis. Therefore, a list of well-known brands facing well-publicised crises was compiled. However, at the same time, we wanted to assess whether there are effect differences based on key distinctions among the cases (Yin, 2017). Therefore, the brands facing crisis situations were categorised as recent crises vs. past crises with a demonstrated recovery (Li and Wei, 2016). A key distinction in the cases that aligns with the aims of the research is the crisis type to enable comparison of effects based on product- or moral harm crises. However, we also note that the selected cases provide some diversity in terms of global scale and business model. This process led to the selection of four companies: Tim Hortons, Subway, Samsung and Air Miles chosen to represent different situational types of brand crisis, as shown in Table 1.

\begin{tabular}{|l|l|l|l|l|l|}
\hline Case & Brand & Progress & Type & Scale & Business Model \\
\hline 1 & Tim Hortons & Recent & Moral & National & Franchised \\
\hline 2 & Subway & Recent & Product & International & Franchised \\
\hline 3 & Samsung & Rebound & Product & International & Non-franchised \\
\hline 4 & Air Miles & Rebound & Moral & National & Non-franchised \\
\hline
\end{tabular}

Table 1: Brand crisis companies selected as cases for analysis.

Tim Hortons (1) is selected as a brand facing crisis based on their response to a public policy change in labour rates which was in contrast with their core identity associated with the 
Canadian working class (Saltzman, 2018). The quick-service restaurant brand faced a crisis in its brand management when the multi-millionaire owner wrote to his employees to erode working conditions following implementation of governmental policy increasing the minimum wage. The letters received by employees stated that in-work breaks would no longer be paid, paradoxically resulting in a drop of overall earnings for many of them. Understandably, disgruntled staff members took to social media and the press to make their opinions known, with a resulting loss in confidence in the brand.

Subway (2) underwent a brand crisis when its chicken was found not to contain enough chicken DNA (Evans and Szeto, 2017). This led to a great deal of reputational damage for the sandwich seller and many franchises were hit by a drop in sales following the revelation. Then, whilst a subsequent lawsuit was launched by Subway in defence of their product, there was little activity to defend the reputation of the brand.

Samsung (3) is selected because of the crisis following the explosion of its mobile phone product with the subsequent refusal of airlines to allow the product on board planes (Farrer, 2016). As a result of its phone batteries bursting into flames and exploding, Samsung faced a huge amount of reputational damage, especially for its Galaxy Note 7, launched in 2016. As a result, the brand said it was accountable and would get to the source of the technical problem. By communicating this and continuing to update stakeholders, including employees and consumers, Samsung turned around the 15 per cent global drop in sales for its mobile phone products. Indeed, commentators have argued the company enhanced its brand identity to include honesty and a culture for solving problems.

Air Miles (4) is selected as a brand that suffered a crisis from angry consumers when it chose to significantly alter its loyalty programme's expiration policy and terms and conditions, by implementing a five year expiry date (Cohn, 2016). The public backlash resulted in the brand facing reputational damage from customers and subsequently its retail partners were dragged into the crisis. Only when Air Miles' parent company decided to publicly back away from its decision, with a resultant loss in revenue, was the brand restored to its former position.

\section{Operationalisation of Variables}

Consistent with previous research (Woodside, 2004), three balance theory variables are considered in this study, namely, brand attitude towards the crisis, consumer attitude towards the brand, and consumer attitude towards the crisis. Consumer attitude is a "set of constructs used to represent [..] general feelings of favourableness-unfavourableness, or how positive or negative one felt about [an] attitudinal object " (Jaccard and Jacoby, 2020, p. 98) such as a product, and represents a key aspect of the consumption process (Solomon, 2017). Sentiment 
analysis is a measure of consumer attitude in text (Mostafa, 2013) and a natural language processing (NLP) technique which interprets and classifies emotion (positive, negative, and neutral). Using lexical analysis and artificial intelligence (AI) techniques the analysis can detect tone, as a measure of polarity. Polarity is the numerical representation based on the words used as between +1 and -1 representing fully positive and fully negative respectively. When large amounts of textual data regarding an issue are extracted over time (such as a crisis), it is then possible to aggregate sentiment as a measure of customer attitudinal change. For example, several studies have used sentiment changes on Twitter to predict outcomes ranging from the US presidential elections (H. Wang, Can, Kazemzadeh, Bar, \& Narayanan, 2012) to stock price fluctuations (Rao and Srivastava, 2012) to box office success (Amolik, Jivane, Bhandari, \& Venkatesan, 2016) highlighting the predictive power of social media.

All of the brands facing crisis within the sample were active on social media during the crisis, and in particular on Twitter and Facebook. J. Xu and Wu (2015) explain that Twitter is often used as tool for public relations by brands and for consumers to express their sentiments about brands in real time (Gilpin, 2010), therefore the final variable relates to the changes in brand management and consumer attitude on Twitter. The variables are defined in Table 2 . In particular, it is worth highlighting that capturing the brand personality communicated by management in social media is an appropriate way to assess their intent (Masiello, Bonetti, \& Izzo, 2020).

\begin{tabular}{|l|l|l|l|}
\hline Variable & Definition & Measure & Time Period \\
\hline $\begin{array}{l}\text { Customer- } \\
\text { Brand }\end{array}$ & $\begin{array}{l}\text { The customer's attitude } \\
\text { towards the brand. }\end{array}$ & $\begin{array}{l}\text { Sentiment analysis (+/-) } \\
\text { change of buzz around the } \\
\text { brand }\end{array}$ & $\begin{array}{l}\text { 3 months } \\
\text { before, } 1 \\
\text { month during, }\end{array}$ \\
\cline { 1 - 2 } Brand-Action & $\begin{array}{l}\text { The brand's attitude towards } \\
\text { the product vs. how the } \\
\text { brand responds to the crisis. }\end{array}$ & $\begin{array}{l}\text { Sentiment analysis (+/-) } \\
\text { change by the brand about } \\
\text { the product or issue. }\end{array}$ & $\begin{array}{l}\text { months } \\
\text { tfter. }\end{array}$ \\
\cline { 1 - 2 } $\begin{array}{l}\text { Customer- } \\
\text { Action }\end{array}$ & $\begin{array}{l}\text { Customers' attitude towards } \\
\text { the product vs. response to } \\
\text { the crisis and how they } \\
\text { process the imbalance. }\end{array}$ & $\begin{array}{l}\text { Sentiment analysis (+/-) } \\
\text { change by customers } \\
\text { around the product or } \\
\text { issue. }\end{array}$ & \\
\cline { 1 - 2 } $\begin{array}{l}\text { Brand } \\
\text { Personality } \\
\text { Changes }\end{array}$ & $\begin{array}{l}\text { The brand personality as } \\
\text { brand's textual content. }\end{array}$ & $\begin{array}{l}\text { Aaker's model of five } \\
\text { brand personality } \\
\text { dimensions: Competence, } \\
\text { Sincerity, Sophistication, } \\
\text { Ruggedness and } \\
\text { Excitement }\end{array}$ & $\begin{array}{l}\text { 3 months after } \\
\text { the event. }\end{array}$ \\
\hline
\end{tabular}

Table 2: Definition and measurement of study variables

\section{Data Collection}

The data collection took place in two phases. First, Twitter tweets were collected using the Twitter Application Programming Interface (API) and Python scripting language. Tweets 
were collected for a timeframe of $+/-3$ months from the date of the event, in line with practitioner recommendations made during a recent crisis (Storey, 2018). This includes tweets by the brand itself and user buzz around the brand. This led to a total of 214,613 tweets for analysis, shown in Table 3 below.

\begin{tabular}{|c|c|c|c|c|c|}
\hline & Brand & Date of Event & $\begin{array}{l}\text { Brand } \\
\text { Sentiment }\end{array}$ & $\begin{array}{l}\text { Customer } \\
\text { Sentiment }\end{array}$ & $\begin{array}{l}\text { Total } \\
\text { Number }\end{array}$ \\
\hline 1 & Tim Hortons & $\operatorname{Jan} 3^{\text {rd, }} 2018$ & 3,458 & 67,552 & 71,010 \\
\hline 2 & Subway & Feb $28^{\text {th }}, 2017$ & 209 & 65,662 & 65,871 \\
\hline 3 & Samsung & Sept $2^{\text {nd }}, 2016$ & 289 & 56,447 & 56,736 \\
\hline \multirow[t]{4}{*}{4} & Air Miles & Nov $29^{\text {th }}, 2016$ & 4,333 & 16,663 & 20,996 \\
\hline & & Total & 8,289 & 206,324 & 214,613 \\
\hline & & Mean & 2,072 & 51,581 & 53,653 \\
\hline & & andard Deviation & 2,136 & 23,779 & 22,558 \\
\hline
\end{tabular}

Table 3: Number of tweets at time of crisis by brand

Data Analysis

The data analysis was conducted in three stages and repeated for each crisis case. All textual data were analysed using the Natural Language Toolkit (NLTK) which facilitates statistical natural language processing of human language data in Python.

In step one, the tweets were categorised into pre-, during and post-crisis. Customer buzz tweets were divided into brand vs. action variables. The consumer attitude and brand tweets were analysed using NLTK and sentiment analysis to determine the attitude of the consumer regarding the crisis of the brand and the action, as well as the brand's reaction concerning the issue.

In step two, the brand tweets were then analysed in the same manner as step one, in order to explore the changes in brand communications before, during and after the crisis, using Opoku, Abratt \& Pitt's (2006) brand personality dictionary that is based upon Aaker's (1996) model of brand personality. Aaker's model enables the measurement of brand personality over five dimensions, namely: Competence, Sincerity, Sophistication, Ruggedness and Excitement. NLTK was used to lemmatise (Stanford) the textual content, and the dictionary analysis was used to extract synonyms (examples are shown in Table 4) related to the five dimensions of Aaker's model. This demonstrated some changes in the positioning of each brand based on brand personality.

\begin{tabular}{|l|l|}
\hline Trait & Synonyms \\
\hline Competence & Competent, outstanding, secure, successful, superior, technical \\
\hline Sincerity & Authentic, charitable, natural, positive \\
\hline Sophistication & Beautiful, elegant, exclusive, luxurious, stunning \\
\hline Ruggedness & Challenge, extreme, hazardous, resilient, tough \\
\hline
\end{tabular}




\begin{tabular}{|l|l}
\hline Excitement & Courageous, exciting, extreme, inspiring, unique \\
\hline
\end{tabular}

Table 4: Examples of synonyms (Opoku's (2005) dictionary)

Finally, step three connected the statistical inferences of the analyses within steps one and two. Analysis of variance (ANOVA) was used to compare the before, during and after crisis to understand any significant differences between the consumer attitude towards the brand and the action, and the brand personality changes over time. Heider's balance theory was calculated and diagrammatically plotted to demonstrate the attitude calculations and significant differences with the brand personality changes before, during and after the crisis.

\section{Case Study Analysis and Findings}

The following four case studies demonstrate the potential of balance theory to extend understanding of brands in crisis.

\section{Tim Hortons Case Study}

The Tim Hortons crisis is an example of a recent moral harm associated with the unfair treatment of employees. Sentiment analysis was calculated before, during and after the crisis for consumer-brand, consumer-action and brand-action, as shown in Table 5. There are statistically significant differences in sentiment as determined by a one way Consumer-Brand $[\mathrm{F}(2,60558)=258.28, \mathrm{p}=.00]$, Consumer-Action $[\mathrm{F}(2,6893)=21.84, \mathrm{p}=.00]$ and Brand-Action $[F(2,3455)=22.24, p=.00]$ sentiment. The post-hoc analysis reveals a significant drop in Consumer-Brand sentiment during $(\mathrm{M}=.03, \mathrm{SD}=.3)$ and an increase after $(\mathrm{M}=.06, \mathrm{SD}=.32)$ the crisis. There is a statistically significant decrease in Consumer-Action sentiment during $(\mathrm{M}=.05$, $\mathrm{SD}=.28)$ and an increase after $(\mathrm{M}=.1, \mathrm{SD}=.3)$ the crisis. Finally, there is a significant increase in brand-action sentiment during $(\mathrm{M}=.32, \mathrm{SD}=.29)$ the crisis.

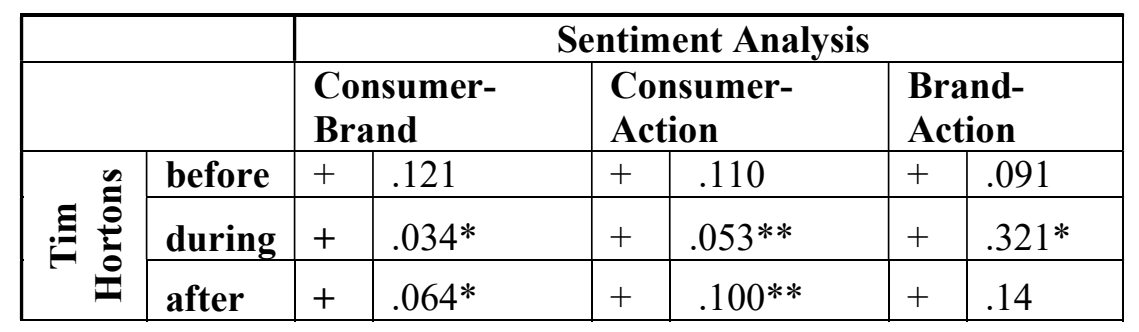

Table 5: Tim Hortons attitudinal changes over time Note. ${ }^{*}$ significantly different at the $<.05$ level, ${ }^{* *}$ significantly different at the $<.01$ level

Dictionary analysis was calculated before, during and after the crisis over the five dimensions of brand personality, as shown in Table 6 . There are statistically significant differences in the brand personality as determined by a one way ANOVA for Competence 
$[F(2,3455)=3.34, p=.04]$ during the crisis. The post-hoc analysis reveals a significant increase in Competence $(\mathrm{M}=.16, \mathrm{SD}=.39)$ after the crisis.

\begin{tabular}{|c|c|c|c|c|c|c|}
\hline & & \multicolumn{5}{|c|}{ Brand Personality Word Count } \\
\hline & & Sincerity & Excitement & Competence & Sophistication & $\begin{array}{l}\text { Rugged- } \\
\text { ness }\end{array}$ \\
\hline \multirow{3}{*}{$\Xi \stackrel{0}{\Xi}$} & before & $501(.17)$ & $290(.07)$ & $253(.14)$ & $23(.01)$ & $41(.01)$ \\
\hline & during & $338(.2)$ & $92(.08)$ & $128(.1)$ & $11(.01)$ & $36(.03)$ \\
\hline & after & $286(.19)$ & $85(.05)$ & $182\left(.16^{*}\right)$ & $12(.01)$ & $40(.02)$ \\
\hline
\end{tabular}

Table 6: Tim Hortons brand personality changes over time

Note. () is the mean, * significantly different at the $<.05$ level

During the crisis, there is no change in brand personality, but Competence increases after it. The triad remains positive, as shown in Figure 2. During crisis, the polarity of Consumer-Brand and Action sentiment weakens and Brand-Action increases. After the crisis, the polarity of Consumer-Brand increases, and Action strengthens significantly. This suggests that Tim Hortons recovered from the moral issue. But the brand does not fully recover, indicating that trying to ignore the issue did not work.

Figure 2: Calculating Heider's balance theory for Tim Hortons
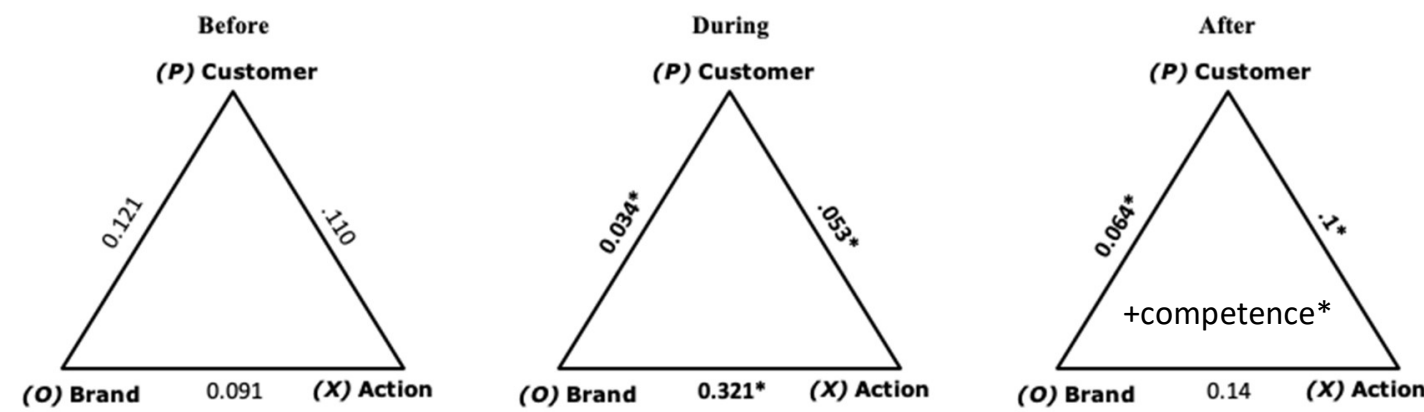

Subway Case Study

The Subway crisis is an example of a recent product-based issue associated with the potential misrepresentation of ingredients. Sentiment analysis was calculated before, during and after the crisis for consumer-brand, consumer-action and brand-action, as shown in Table 7. There are statistically significant differences determined by a one way ANOVA for ConsumerBrand $[F(2,65659)=1063.63, p=.00]$, Consumer-Action $[F(2,7846)=163.38, p=.00]$ and Brand-Action $[\mathrm{F}(2,206)=1.03, \mathrm{p}=.04]$. The post-hoc analysis reveals a significant drop in Consumer-Brand sentiment during $(\mathrm{M}=-.01, \mathrm{SD}=.33)$ and an increase after $(\mathrm{M}=.06, \mathrm{SD}=.3)$ the crisis. It also reveals a significant drop in Consumer-Action sentiment during $(\mathrm{M}=.14, \mathrm{SD}=.38)$ and an increase after $(\mathrm{M}=-.03, \mathrm{SD}=.38)$ the crisis. Finally, there is a significant decrease in Brand-Action sentiment during $(\mathrm{M}=.25, \mathrm{SD}=.37)$ the crisis. After the crisis, the Brand-Action sentiment appears to recover to before the crisis levels. 


\begin{tabular}{|c|c|c|c|c|c|c|c|}
\hline & \multicolumn{6}{|c|}{ Sentiment Analysis } \\
\hline & & & umer-Brand & & Imer-Action & & d-Action \\
\hline \multirow{3}{*}{ 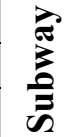 } & before & + & .157 & + & .041 & + & .105 \\
\hline & during & + & $.014 * *$ & - & $.139 * *$ & + & $.254^{*}$ \\
\hline & after & + & $.063 * *$ & - & $.032 * *$ & + & .161 \\
\hline
\end{tabular}

Table 7: Subway's attitudinal changes over time

Note. ${ }^{*}$ significantly different at the $<.05$ level, ${ }^{* *}$ at the $<.01$ level

Dictionary analysis was calculated before, during and after the crisis over the five dimensions of brand personality, as shown in Table 8 . There are statistically significant differences in brand personality as determined by a one way ANOVA for Sincerity $[F(2,206)=17.82, p=.00]$. The post-hoc analysis reveals a significant increase in Sincerity during $(\mathrm{M}=.7, \mathrm{SD}=.48)$ and a decrease after $(\mathrm{M}=.1, \mathrm{SD}=.3)$ the crisis. The increase in the Sincerity dimension was not expected by the hypothesis for the performance-based crisis.

\begin{tabular}{|l|l|l|l|l|l|l|}
\hline \multicolumn{2}{|c|}{} & \multicolumn{5}{|c|}{ Brand Personality Word Count } \\
\hline \multicolumn{2}{|c|}{} & Sincerity & Excitement & Competence & Sophistication & $\begin{array}{l}\text { Rugged- } \\
\text { ness }\end{array}$ \\
\hline \multirow{2}{*}{\begin{tabular}{c}
$*$ \\
\multirow{2}{*}{}
\end{tabular}} & before & $13(.09)$ & $12(.08)$ & $9(.06)$ & 0 & $4(.03)$ \\
\cline { 2 - 7 } & during & $7\left(.7^{*}\right)$ & $5(.5)$ & $1(.1)$ & 0 & $1(.1)$ \\
\cline { 2 - 7 } & after & $5\left(.1^{*}\right)$ & $2(.04)$ & $2(.04)$ & $2(.04)$ & $3(.06)$ \\
\hline
\end{tabular}

Table 8: Subway's brand personality changes over time

Note. () is the mean, * significantly different at the $<.05$ level

Figure 3 shows that during the crisis, Sincerity increases and then decreases after the crisis. Within this context, the triangle becomes unbalanced during the crisis, indicating cognitive dissonance. After the crisis, the polarity of Consumer-Brand sentiment strengthens, but the issue remains indicating that a more active crisis management approach was needed, rather than simply being "sincerely" sorry.

Figure 3: Calculating Heider's balance theory for Subway
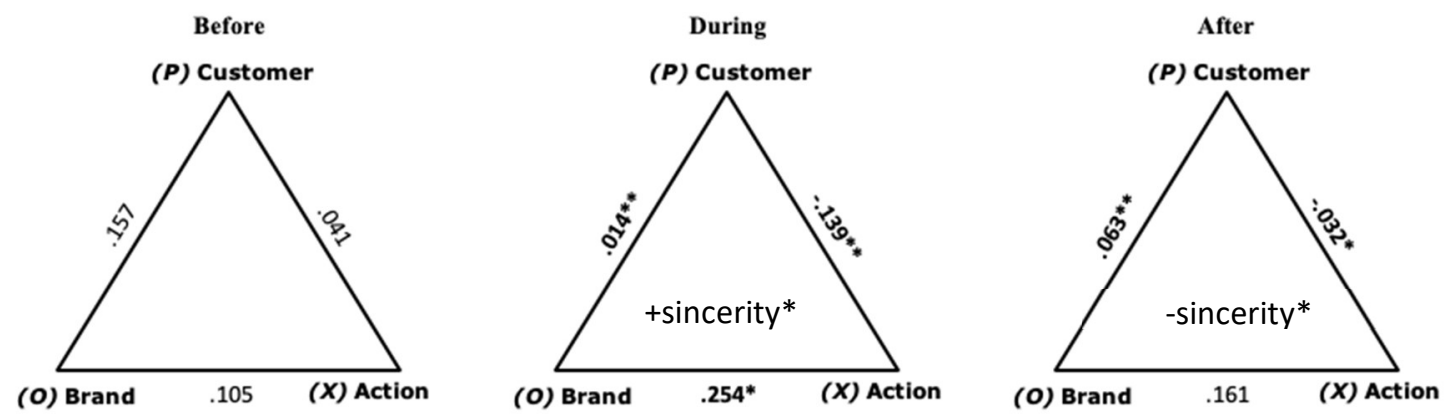

Samsung Case Study

The Samsung crisis is an example of product harm recovery with battery-based explosions. Sentiment analysis was calculated before, during and after the crisis for Consumer- 
Brand, Consumer-Action and Brand-Action, as shown in Table 9. There are statistically significant differences as determined by a one way ANOVA Consumer-Action $[\mathrm{F}(2,7410)$ $=7.81, \mathrm{p}=.00]$. The post-hoc analysis reveals a significant decrease in Consumer-Action sentiment during $(\mathrm{M}=.02, \mathrm{SD}=.12)$ the crisis.

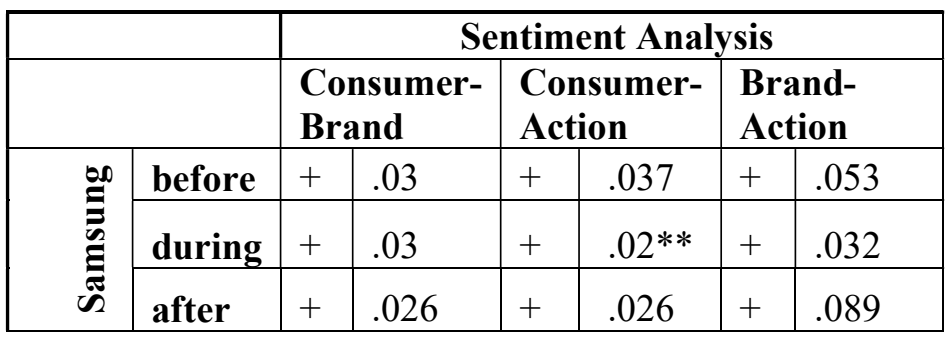

Table 9: Samsung's attitudinal changes over time Note. $* *$ significantly different at the $<.01$ level

Dictionary analysis was calculated before, during and after the crisis over the five dimensions of brand personality, as shown in Table 10 . There are statistically significant differences in brand personality as determined by a one way ANOVA for Competence $[\mathrm{F}(2,142)=1.79, \mathrm{p}=.00]$. The post-hoc analysis reveals a significant increase in Competence during $(\mathrm{M}=.27, \mathrm{SD}=.87)$ the crisis.

\begin{tabular}{|c|c|c|c|c|c|c|}
\hline & & \multicolumn{5}{|c|}{ Brand Personality Word Count } \\
\hline & & Sincerity & Excitement & Competence & Sophistication & $\begin{array}{l}\text { Rugged- } \\
\text { ness }\end{array}$ \\
\hline \multirow{3}{*}{ 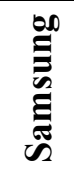 } & before & $1(.05)$ & $3(.14)$ & $2(.1)$ & 0 & 0 \\
\hline & during & $10(.24)$ & $11(.27)$ & $11(.27 *)$ & $2(.05)$ & 0 \\
\hline & after & $11(.13)$ & $24(.29)$ & $15(.18)$ & $4(.02)$ & $1(.01)$ \\
\hline
\end{tabular}

Table 10: Samsung's brand personality changes over time

Note. () is the mean, * significantly different at the $<.05$ level

Figure 4 shows that during the crisis, Competence increases and remains high afterwards. All the relationships remain balanced as positive. During the crisis, sentiment from the consumer about the brand's action decreases. After the crisis, Brand-Action increases slightly, but is not significant. While the recovery is not complete for the brand, it is in the right direction. This could indicate that ownership of the crisis helps the brand to recover. 
Figure 4: Calculating Heider's balance theory for Samsung
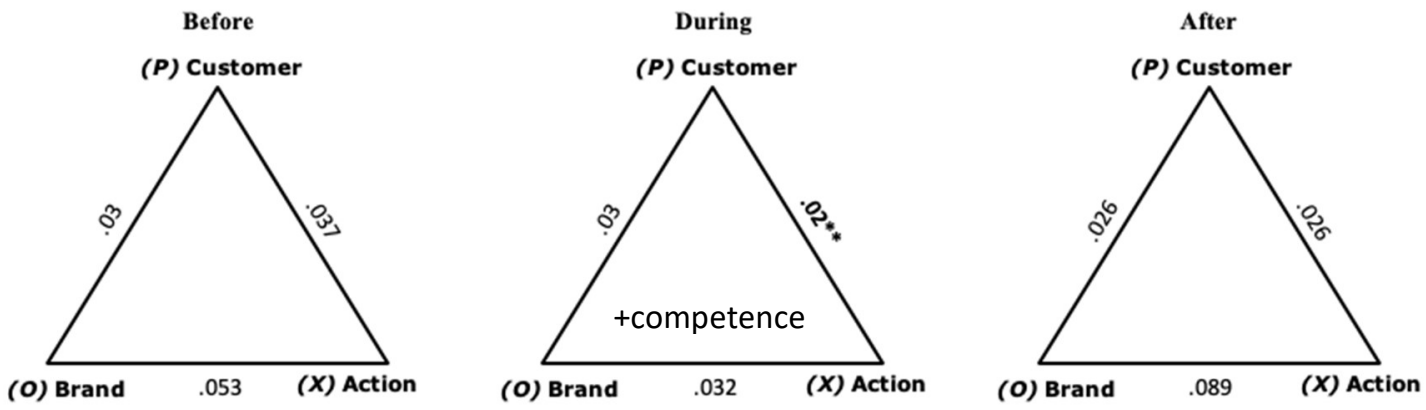

\section{Air Miles Case Study}

The Air Miles crisis is an example of moral harm recovery when the company changed its policy to allow for the expiry of loyalty points. Sentiment analysis was calculated before, during and after the crisis for Consumer-Brand, Consumer-Action and Brand-Action, as shown in Table 11. There are statistically significant differences determined by a one way ANOVA for Consumer-Brand $[\mathrm{F}(2,10147)=1.35, \mathrm{p}=.00]$ and Brand-Action $[\mathrm{F}(2,4096)=12.68, \mathrm{p}=.00]$. The post-hoc analysis reveals a significant drop in Consumer-Brand sentiment during $(\mathrm{M}=.06$, $\mathrm{SD}=.37)$ and a further drop after $(\mathrm{M}=.04, \mathrm{SD}=.3)$ the crisis. It also reveals a significant drop in Brand-Action sentiment during $(\mathrm{M}=.07, \mathrm{SD}=.29)$ and an increase after $(\mathrm{M}=.14, \mathrm{SD}=.35)$ the crisis.

\begin{tabular}{|c|c|c|c|c|c|c|c|}
\hline & \multicolumn{6}{|c|}{ Sentiment Analysis } \\
\hline & & & Imer-Brand & & ner-Action & & d-Action \\
\hline \multirow{3}{*}{$\because \frac{\mathscr{e}}{\dot{*}}$} & before & + & .111 & + & .024 & + & .129 \\
\hline & during & + & $.063^{*}$ & + & .008 & + & $.074^{*}$ \\
\hline & after & + & $.041^{*}$ & + & .025 & + & $.138^{*}$ \\
\hline
\end{tabular}

Table 11: Air Miles' attitudinal changes over time

Note. * significantly different at the $<.05$ level

Dictionary analysis was calculated before, during and after the crisis over the five dimensions of brand personality, as shown in Table 12. There are statistically significant differences in brand personality as determined by a one way ANOVA for Excitement $[\mathrm{F}(2,4096)=8.545, \mathrm{p}=.00]$ and Competence $[\mathrm{F}(2,4096)=5.166, \mathrm{p}=.01]$. The post-hoc test reveals the dimension of Excitement significantly lowers $(\mathrm{M}=.08, \mathrm{SD}=.39)$ during and Competence significantly increases $(\mathrm{M}=.08, \mathrm{SD}=.47)$ after the crisis.

\begin{tabular}{|c|c|c|c|c|c|c|}
\hline & \multicolumn{5}{|c|}{ Brand Personality Word Count } \\
\hline & & Sincerity & Excitement & Competence & Sophistication & $\begin{array}{l}\text { Rugged- } \\
\text { ness }\end{array}$ \\
\hline \multirow{3}{*}{$\because \frac{\mathscr{\sigma}}{2}$} & before & $501(.26)$ & $290(.15)$ & $253(.13)$ & $23(.01)$ & $41(.02)$ \\
\hline & during & $338(.31)$ & $92\left(.08^{* *}\right)$ & $128(.12)$ & $11(.01)$ & $36(.03)$ \\
\hline & after & $286(.27)$ & $85(0.08)$ & $182(.17 *)$ & $12(.01)$ & $40(.03)$ \\
\hline
\end{tabular}


Table 12: Air Miles' brand personality changes over time

Note. () is the mean, * significantly different at the $<.05$ level, $* *$ at the $<.01$ level

Figure 5 shows that during the crisis Excitement decreases, while Competence increases after the crisis. The triad of relationships are positive throughout. Sentiment weakens for Consumer-Brand and Consumer-Action. After the polarity, Consumer-Brand weakens even more and Brand-Action strengthens. The brand personality becoming less exciting did not seem to aid brand recovery.

Figure 5: Calculating Heider's balance theory for Air Miles
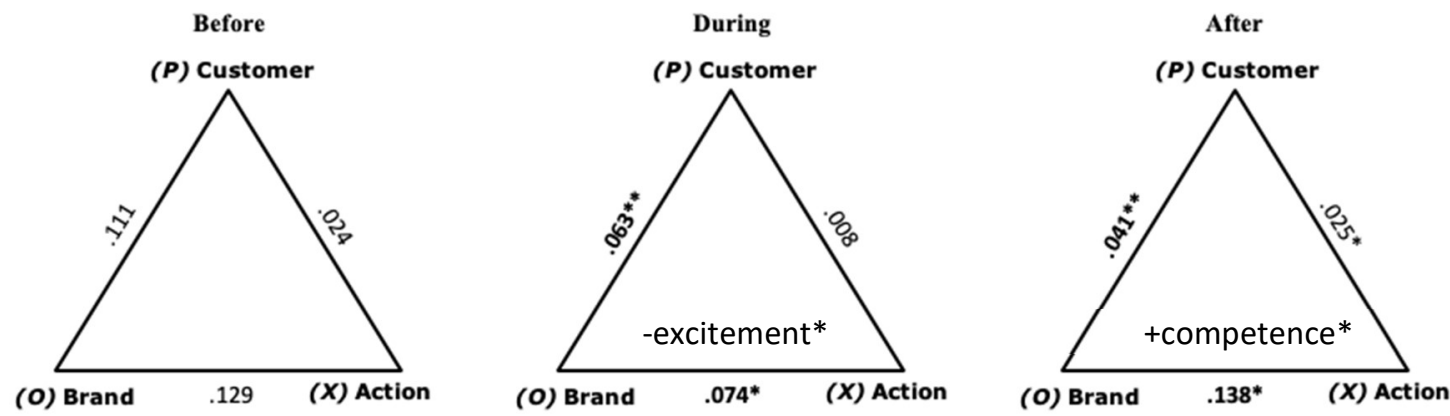

Hypotheses Summary

The hypotheses were guided by the literature to develop a deeper understanding about how attitude and brand personality changes occur through a crisis situation. The first hypothesis stated expectations that attitudes toward the brand, crisis and response would unbalance during a crisis and rebalance after the crisis. The hypothesis is directionally supported in the four case studies with significant shifts in consumer attitudes demonstrating that crisis affects critical attitudinal objects in the relationship triad. However, this is a superficial conclusion because the pattern of attitude changes over the three time periods suggests that crisis effects on sentiment are more complicated. The pattern of changes is similar for the Tim Hortons and Subway crises. In these two cases, Consumer-Brand and ConsumerAction sentiment decreased during the crisis but increased in the period after the crisis. Although, in the case of the Subway product harm crisis, the Consumer-Action sentiment weakened to a negative status unbalancing the triadic relationships. In addition, in both cases, the Brand-Action sentiment increased during the crisis without a significant change following the crisis. The other two cases exhibited entirely different patterns of attitude changes in triadic relationships relevant to the crisis. The Samsung product harm crisis experienced only one significant attitude change as consumer-action decreased during the crisis. However, the Air Miles moral harm crisis lead to a significant drop in Consumer-Brand sentiment and Brand- 
Action during the crisis. While Consumer-Brand sentiment continued to decrease after the Air Miles crisis, Brand-Action sentiment experienced a significant improvement.

The second hypothesis was generally phrased with the expectation that there would be changes in brand personality dimensions when comparing pre-, during and post-crisis timeframes of both crisis types. The hypothesis is supported in all cases as brand personality dimensions show shifts during and after the crisis. However, like the attitude change results, the pattern of brand personality changes observed presents a complicated picture. Of the four cases, three experienced changes in brand personality during the crisis situation: Subway (+ Sincerity), Samsung (+ Competence), and Air Miles (- Excitement). Subsequently, two brands had significant changes in Twitter activity after the crisis period, as Subway decreased in the Sincerity dimension and Air Miles had an increase in the Competence dimension. There was no significant change for Samsung's brand personality after the crisis. The Tim Hortons case is the one case where a significant change in brand personality was observed in Twitter activity only after the crisis (+ Competence). In terms of crisis type, it is important to note that the Competence dimension of brand personality was significantly higher in the post-crisis time periods for both moral harm cases (Tim Hortons and Air Miles). This did not occur in the product harm cases (Subway and Samsung).

\section{Discussion and Managerial Implications}

Despite the significant repositioning of brands facing a crisis, little research has looked into how companies attempt to manage themselves through a crisis. This is perhaps because, until recently, brands were able to let a crisis pass without large interventions or following a strategy in any coherent and consistent way. Social media has put the power into the hands of consumers, yet the behaviour of a brand can influence the rhetoric and potentially limit attitudinal damage.

Therefore, the purpose of this research was to understand the process of attitude changes towards a brand through a crisis and the brand's communication around the crisis. The findings of this paper highlight the importance of management within the context of the crisis. Specifically, the results show significant shifts in online consumer and brand attitudes. However, there are very few instances where the sentiments turn negative for the brand. There was only one case where the triangle of brand relationships became unbalanced. In this case of Subway, the Consumer-Action sentiment flipped to negative during the crisis and remained there in the post-crisis measurement. While brand managers should be striving to re-establish a positive and balanced triangle of brand relationships, Baxter and Ilicic (2015) showed that brand 
purchases remain a possibility in the positive imbalance situation. Therefore, the results of the current research do not predict a disaster for Subway. Nonetheless, the instances of few unbalanced triads is interesting for marketing practice because it may result from counterarguments provided by brand advocates (Mishra and Sharma, 2019) or from a strong brand protecting the negative influence of a crisis (Rea, et al., 2014).

Integrating the concept of brand personality into this research design of different crisis types highlights some important findings. Whilst previous research has explored proactive management of brand personality communication over time (Rutter, Nadeau, Aagerup, \& Lettice, 2019), this research examined reactive crisis management. Indeed, a moral harm crisis situation seems to provide an opportunity for the brand to establish the Competence dimension of the brand personality identity as more positive. Han, et al. (2018) explain that being sincerely sorry about the actions which caused a crisis could help the brand to recover. However, our findings indicate that brands focused on improving the Competence score for moral harm cases rather than improving the brand's Sincerity dimension. Further, in the product harm crisis for Subway, while Sincerity increased during the crisis, it later weakened on the same dimension. This likely reflects the steadfast position of the brand on their product rather than fixing the underlying issue. In contrast, Samsung suffered from a product harm crisis and significantly increased their Competence levels during the crisis by recalling the product, at great expense. This recovery position was maintained after the crisis abated, with Samsung turning a negative event into a positive effect, through active management of the crisis (Liu, et al., 2017).

\section{Theoretical Contributions}

This research presents ideas to develop balance theory in brand crisis management. Balance theory is shown to explain changes in consumer attitude mapped through a crisis. While recent research has already demonstrated balance theory as a powerful lens to understand salient brand relationships (Baxter and Ilicic, 2015; Hammerl, et al., 2016; Yun, et al., 2019), the temporal mapping of changes in the relational triad has received little attention (S. Roy, et al., 2012). The current research shows that sentiment changes do occur in a relationship triad but the patterns of change are not consistent across the four cases. For example, during the Samsung crisis, there was only one significant change in sentiment - a decline in ConsumerAction sentiment. While the Tim Hortons and Subway cases shared that decline in ConsumerAction, there were other changes observed in these crises and in the Air Miles crisis. Therefore, the pattern of effects are complicated and rooted in different factors. 
The literature suggests a key factor is the type of crisis experienced by the brand as either product harm (S. Lee and Atkinson, 2019; Liu, et al., 2017; Rea, et al., 2014; V. Roy, et al., 2018; Souiden and Pons, 2009) or moral harm (Baghi and Gabrielli, 2019; Hegner, et al., 2018; Thaler, et al., 2018). However, this categorisation does not provide a high level of explanatory power in understanding the different patterns of crisis effects on attitudes. When comparing the case results in the current research, the pattern of attitude changes does not seem to be reliant upon crisis type. For instance, the two moral type crises and the two product type crises each only share one directional sentiment change. Therefore, while the literature guides us towards a product versus moral harm dichotomy, the impact of a brand crisis seems to be more complicated. The results suggest that business model or product category is a useful factor to explain attitude changes in a brand crisis. The two recent crisis cases (Tim Hortons and Subway) represent different crises types yet are similar on the basis of business model (franchise) as well as product category (quick-service restaurants).

While the crisis type does not seem to wholly explain differences in attitude changes in a crisis, this research sought to extend balance theory using brand personality. Indeed, some of Aaker's (1997) brand personality dimensions (i.e. competence and sincerity) are conceptually consistent with the product and moral harm classification of crisis types. Product harm crises are about the competence of the brand to deliver a functioning and safe product to the consumer, while moral harm crises represent failures in character that are not a sincere representation of the brand. This current research found changes in both Competence and Sincerity brand personality dimensions in the crisis cases as well as Excitement in one case. Previous research highlighted Exciting brands were able to maintain loyalty during high complaint situations (Rutter, Chalvatzis, Roper, \& Lettice, 2018); however, our findings suggest this may not hold in a larger scale crisis. Of note, is the consistent increase in Competence for the moral harm crisis cases after the crisis has passed. These results demonstrate that the extension of balance theory to account for brand Competence and Sincerity in the context of crises can help explain how attitudes change in a crisis.

\section{Managerial Implications}

The theory and results of this research provide some initial guidance for brand managers facing a crisis. This research reinforces the importance of online communication and this should not be ignored in a crisis. There are significant changes in consumer and brand attitudes expressed online, so attention and active engagement is needed. The extension of balance theory to include brand personality also has some practical implications. Brand personality can be a powerful lens for brand managers to frame their online communication for consistency with the values of the brand. However, the legacy of the crisis may be a resilient 
shift in the brand personality identity. The crisis is a formidable force and an unfreezing opportunity which seems to result in consistent brand personality profiles for crisis survivors. D. Aaker (1996) argued that big shifts in brand personality should be avoided and incremental changes should only be made to reposition the brand image over time to avoid cognitive dissonance. Our findings show that changes in brand personality communication do occur with the disruption of a crisis. In particular, the dimensions of Sincerity and Competence seem more active in a crisis. A brand can therefore take a negative situation as an opportunity for a “competent" fix (Hegner, et al., 2018). Brand managers may ask themselves, why waste a good crisis?

\section{Limitations and Future Research}

This research was designed as a four case study analysis of crisis situations. While case study research can provide powerful understanding of how and why a phenomenon occurs (Yin, 2017), the approach does not deliver generalisable results as they remain case specific. However, this research does use a multiple case study design to enable the comparison of key differences as well as broaden the impact of findings. In addition, the cases do share some similar features which enable the comparison and comment on patterned effects.

Our results suggest that attitude changes towards a brand in crisis is more complicated than the literature would suggest. Future research can further develop this balance theory and crisis type extension by examining more brands in crisis to identify consistent patterns over cases. This would aid in the development of a generalisable theory for brand crises. There should be an analysis of additional factors as a means of a stronger explanation of brand recovery. In this research, we observed a similar pattern of effects for quick-service restaurants and previous research showed that a strong brand image can have a prophylactic effect in a crisis (Rea, et al., 2014). Additional factors like these should be explored using balance theory and brand personality in future research. In particular, the inclusion of brand personality to better understand a brand crisis is an understudied approach. Future research should collect and analyse the brand personality over time from the brand identity perspective but also from the consumer perception perspective. Finally, this study focuses on one social media platform (i.e. Twitter) so future testing of the theory extension should include other platforms, such as YouTube, Facebook, Blogs and other emergent social media channels.

\section{References}

Aaker, D. (1996). Building strong brands New York: Free Press. 
Aaker, J. (1997). Dimensions of brand personality. Journal of marketing research, 34(3), pp. 347-356.

Aaker, J., Vohs, K. D., \& Mogilner, C. (2010). Nonprofits Are Seen as Warm and ForProfits as Competent: Firm Stereotypes Matter. Journal of consumer research, 37(2), pp. 224-237.

Amolik, A., Jivane, N., Bhandari, M., \& Venkatesan, M. (2016). Twitter sentiment analysis of movie reviews using machine learning techniques. international Journal of Engineering and Technology, 7(6), pp. 1-7.

Baghi, I., \& Gabrielli, V. (2019). The role of crisis typology and cultural belongingness in shaping consumers' negative responses towards a faulty brand. Journal of Product \& Brand Management, 28(5), pp. 653-670.

Baxter, S. M., \& Ilicic, J. (2015). Three's company: Investigating cognitive and sentiment unit imbalance in co-branding partnerships. Journal of Brand Management, 22(4), pp. 281-298.

Bennett, A. M., \& Hill, R. P. (2012). The universality of warmth and competence: A response to brands as intentional agents. Journal of Consumer Psychology, 22(2), pp. 199-204.

Bergkvist, L. (2017). Celebrity trait transference: when brands pick up endorsers' personality traits. International Journal of Advertising, 36(5), pp. 663-681.

Beverland, M., \& Lindgreen, A. (2010). What makes a good case study? A positivist review of qualitative case research published in Industrial Marketing Management, 1971-2006. Industrial Marketing Management, 39(1), pp. 56-63.

Bosnjak, M., Bochmann, V., \& Hufschmidt, T. (2007). Dimensions of brand personality attributions: a person-centric aproach in the German cultural context. Social Behavior and Personality: an international journal, 35(3), pp. 303-316.

Brehm, J. W., \& Cohen, A. R. (1962). Explorations in cognitive dissonance.

Cartwright, D., \& Harary, F. (1956). Structural balance: a generalization of Heider's theory. Psychological review, 63(5), p 277.

Cohn, M. R. (2016). Loyalty doesn’t go the distance with Air Miles: Cohn. Retrieved Date Accessed, 2019 from https://www.thestar.com/news/queenspark/2016/11/29/loyalty-doesnt-go-thedistance-with-air-miles-cohn.html.

Copulsky, J. R. (2011). Brand resilience: managing risk and recovery in a high-speed world: St. Martin's Press. 
Dawar, N., \& Lei, J. (2009). Brand crises: The roles of brand familiarity and crisis relevance in determining the impact on brand evaluations. Journal of Business Research, 62(4), pp. 509-516.

Evans, P., \& Szeto, E. (2017). What's in your chicken sandwich? DNA test shows Subway sandwiches could contain just 50\% chicken. Retrieved Date Accessed, 2019 from https://www.cbc.ca/news/business/marketplace-chicken-fast-food1.3993967.

Farrer, M. (2016). This article is more than 2 years old Samsung recalls Galaxy Note 7 phones after battery fires. Retrieved Date Accessed, 2019 from https://www.theguardian.com/technology/2016/sep/03/samsung-recalls-galaxynote-7-phones-after-battery-fires.

Fiske, S., Cuddy, A., \& Glick, P. (2007). Universal dimensions of social cognition: Warmth and competence. Trends in Cognitive Sciences, 11(2), pp. 77-83.

Fiske, S., Malone, C., \& Kervyn, N. (2012). Brands as intentional agents: Our response to commentaries. Journal of Consumer Psychology, 22(2), pp. 205-207. doi:https://doi.org/10.1016/j.jcps.2011.12.002 Retrieved from http://www.sciencedirect.com/science/article/pii/S1057740812000320

Fiske, S. T., Malone, C., \& Kervyn, N. (2012). Brands as intentional agents: Our response to commentaries. Journal of Consumer Psychology, 22(2), pp. 205207.

Gilpin, D. (2010). Organizational image construction in a fragmented online media environment. Journal of Public Relations Research, 22(3), pp. 265-287.

Hammerl, M., Dorner, F., Foscht, T., \& Brandstätter, M. (2016). Attribution of symbolic brand meaning: the interplay of consumers, brands and reference groups. Journal of Consumer Marketing, 33(1), pp. 32-40.

Han, J., Sung, Y. H., \& Kim, D. H. (2018). Brand personality usage in crisis communication in Facebook. Journal of Promotion Management, 24(6), pp. 798-819.

Hegner, S. M., Beldad, A. D., \& Hulzink, R. (2018). An experimental study into the effects of self-disclosure and crisis type on brand evaluations-the mediating effect of blame attributions. Journal of Product \& Brand Management, 27(5), pp. 534-544.

Heider, F. (1958). The psychology of interpersonal relations: John Wiley \& Sons. 
Herhausen, D., Ludwig, S., Grewal, D., Wulf, J., \& Schoegel, M. (2019). Detecting, preventing, and mitigating online firestorms in brand communities. Journal of marketing, 83(3), pp. 1-21.

Hur, Y., Lim, C. H., Won, D.-C., \& Kwon, S.-Y. (2018). Types of Brand Transgressions and Consumers' Moral Reasoning Strategies on an Endorser. Sport Marketing Quarterly, 27(4), pp. 275-286.

Jaccard, J., \& Jacoby, J. (2020). Theory Construction and Model-Building Skills, Second Edition: A Practical Guide for Social Scientists: Guilford Publications.

Klipfel, J. A., Barclay, A. C., \& Bockorny, K. M. (2014). Self-Congruity: A Determinant of Brand Personality. Journal of Marketing Development \& Competitiveness, 8(3), pp. 130-144.

Lee, J., \& Kwak, D. (2016). Consumers' responses to public figures' transgression: Moral reasoning strategies and implications for endorsed brands. Journal of Business Ethics, 137(1), pp. 101-113.

Lee, S., \& Atkinson, L. (2019). Never easy to say "sorry": Exploring the interplay of crisis involvement, brand image, and message appeal in developing effective corporate apologies. Public Relations Review, 45(1), pp. 178-188.

Li, M., \& Wei, H. (2016). How to save brand after crises? A literature review on brand crisis management. American Journal of Industrial and Business Management, 6(2), pp. 89-96.

Liu, Y., Shankar, V., \& Yun, W. (2017). Crisis management strategies and the longterm effects of product recalls on firm value. Journal of marketing, 81(5), pp. $30-48$.

MacInnis, D. J. (2012). "Brands as Intentional Agents": Questions and extensions. Journal of Consumer Psychology, 22(2), pp. 195-198. doi:https://doi.org/10.1016/j.jcps.2011.10.004 Retrieved from http://www.sciencedirect.com/science/article/pii/S1057740812000307

Masiello, B., Bonetti, E., \& Izzo, F. (2020). Multiple identities of a festival. International Journal of Contemporary Hospitality Management

Mishra, M. S., \& Sharma, R. W. (2019). Brand Crisis-Sentiment Analysis of UserGenerated Comments About@ Maggi on Facebook. Corporate Reputation Review, 22(2), pp. 48-60.

Mostafa, M. M. (2013). More than words: Social networks' text mining for consumer brand sentiments. Expert Systems with Applications, 40(10), pp. 4241-4251. 
Okazaki, S. (2006). Excitement or sophistication? A preliminary exploration of online brand personality. International Marketing Review, 23(3), pp. 279-303.

Opoku, R., Abratt, R., \& Pitt, L. (2006). Communicating brand personality: Are the websites doing the talking for the top South African Business Schools? Journal of Brand Management, 14(1), pp. 20-39. doi:10.1057/palgrave.bm.2550052 Retrieved from https://doi.org/10.1057/palgrave.bm.2550052

Orth, U. R., Hoffmann, S., \& Nickel, K. (2019). Moral decoupling feels good and makes buying counterfeits easy. Journal of Business Research, 98, pp. 117-125.

Pace, S., Balboni, B., \& Gistri, G. (2017). The effects of social media on brand attitude and WOM during a brand crisis: Evidences from the Barilla case. Journal of Marketing Communications, 23(2), pp. 135-148.

Plummer, J. T. (2000). How personality makes a difference. Journal of Advertising Research, 40(06), pp. 79-84.

Rao, T., \& Srivastava, S. (2012). Analyzing stock market movements using twitter sentiment analysis.

Rauschnabel, P. A., Kammerlander, N., \& Ivens, B. S. (2016). Collaborative brand attacks in social media: exploring the antecedents, characteristics, and consequences of a new form of brand crises. Journal of Marketing Theory and Practice, 24(4), pp. 381-410.

Rawlings, C. M., \& Friedkin, N. E. (2017). The structural balance theory of sentiment networks: Elaboration and test. American Journal of Sociology, 123(2), pp. 510548.

Rea, B., J. Wang, Y., \& Stoner, J. (2014). When a brand caught fire: the role of brand equity in product-harm crisis. Journal of Product \& Brand Management, 23(7), pp. 532-542.

Roy, S., Gammoh, B. S., \& Koh, A. C. (2012). Predicting the effectiveness of celebrity endorsements using the balance theory. Journal of Customer Behaviour, 11(1), pp. 33-52.

Roy, V., Tata, S. V., \& Parsad, C. (2018). Consumer response to brand involved in food safety scandal: An exploratory study based on a recent scandal in India. Journal of Consumer Behaviour, 17(1), pp. 25-33.

Rutter, R., Chalvatzis, K. J., Roper, S., \& Lettice, F. (2018). Branding Instead of Product Innovation: A Study on the Brand Personalities of the UK's Electricity Market. European Management Review, 15(2), pp. 255-272. 
Rutter, R., Nadeau, J., Aagerup, U., \& Lettice, F. (2019). The Olympic Games and associative sponsorship: Brand personality identity creation, communication and congruence. Internet Research, ahead-of-print(ahead-of-print.)Retrieved from https://doi.org/10.1108/INTR-07-2018-0324

Saltzman, A. (2018). Tim Hortons heirs cut paid breaks and worker benefits after minimum wage hike, employees say. Retrieved Date Accessed, 2019 from https://www.cbc.ca/news/business/tim-horton-s-tims-timmies-doubledoubleminimum-wage-ontario-kathleen-wynne-labour-1.4470215.

Scholz, J., \& Smith, A. N. (2019). Branding in the age of social media firestorms: how to create brand value by fighting back online. Journal of Marketing Management, pp. 1-35.

Solomon, M. R. (2017). Consumer Behavior: Buying, Having, and Being: Pearson.

Souiden, N., \& Pons, F. (2009). Product recall crisis management: the impact on manufacturer's image, consumer loyalty and purchase intention. Journal of Product \& Brand Management, 18(2), pp. 106-114.

Stake, R. E. (2006). Multiple case study analysis. New York, NY. Guilford Press. Strain, PS, \& Bovey, EH (2011). Randomized controlled trial of the LEAP model of early intervention for young children with Autism Spectrum Disorders. Topics in Early childhood Special Education, 31, pp. 133-154.

Storey, G. (2018). Six crisis management lessons from top brands at \#PRWCRISIS. Retrieved Date Accessed, 2019 from https://polpeo.com/six-crisis-managementlessons-from-top-brands-at-prwcrisis/.

Thaler, V. S., Herbst, U., \& Merz, M. A. (2018). A real product scandal's impact on a high-equity brand: a new approach to assessing scandal impact. Journal of Product \& Brand Management, 27(4), pp. 427-439.

Vafeiadis, M., Bortree, D. S., Buckley, C., Diddi, P., \& Xiao, A. (2019). Refuting fake news on social media: nonprofits, crisis response strategies and issue involvement. Journal of Product \& Brand Management, ahead-of-print. (aheadof-print.)

Veil, S. R., Buehner, T., \& Palenchar, M. J. (2011). A work-in-process literature review: Incorporating social media in risk and crisis communication. Journal of contingencies and crisis management, 19(2), pp. 110-122. 
Wang, H., Can, D., Kazemzadeh, A., Bar, F., \& Narayanan, S. (2012). A system for real-time twitter sentiment analysis of 2012 us presidential election cycle. Proceedings of the ACL 2012 system demonstrations.

Wang, L., Wang, S., Keller, L. R., \& Li, J. (2016). Thinking styles affect reactions to brand crisis apologies. European Journal of Marketing, 50(7/8), pp. 1263-1289.

Woodside, A. G. (2004). Advancing means-end chains by incorporating Heider's balance theory and Fournier's consumer-brand relationship typology. Psychology \& Marketing, 21(4), pp. 279-294.

Woodside, A. G., \& Chebat, J. C. (2001). Updating Heider's balance theory in consumer behavior: A Jewish couple buys a German car and additional buying-consuming transformation stories. Psychology \& Marketing, 18(5), pp. 475-495.

Xia, L. (2013). Effects of companies' responses to consumer criticism in social media. International Journal of Electronic Commerce, 17(4), pp. 73-100.

$\mathrm{Xu}, \mathrm{J} .$, \& Wu, Y. (2015). Using Twitter in crisis management for organizations bearing different country-of-origin perceptions. Journal of Communication Management, 19(3), pp. 239-253.

Xu, K., \& Li, W. (2013). An ethical stakeholder approach to crisis communication: A case study of Foxconn's 2010 employee suicide crisis. Journal of Business Ethics, 117(2), pp. 371-386.

Yang, A., \& Bentley, J. (2017). A balance theory approach to stakeholder network and apology strategy. Public Relations Review, 43(2), pp. 267-277.

Yannopoulou, N., Koronis, E., \& Elliott, R. (2011). Media amplification of a brand crisis and its affect on brand trust. Journal of Marketing Management, 27(5-6), pp. 530-546.

Yin, R. K. (2017). Case study research and applications: Design and methods: Sage publications.

Yorkston, E. A., Nunes, J. C., \& Matta, S. (2010). The malleable brand: The role of implicit theories in evaluating brand extensions. Journal of marketing, 74(1), pp. 80-93.

Yun, J. T., Duff, B. R., Vargas, P., Himelboim, I., \& Sundaram, H. (2019). Can we find the right balance in cause-related marketing? Analyzing the boundaries of balance theory in evaluating brand-cause partnerships. Psychology \& Marketing, 36(11), pp. 989-1002. 
Zhang, X. A., \& Borden, J. (2017). Linking Issue Management, Corporate Social Responsibility and Crisis Communication: Applying Balance Theory in Crisis and Issue Management. Journal of contingencies and crisis management, 25(4), pp. 209-222. 